\title{
A Study on the Influence of Paternalistic Leadership on Organizational Commitment: Focus on the Mediating Effect of Organizational Identification
}

\author{
Huanhuan Wang and Kim Jong Kwan
}

\begin{abstract}
Rooted in the Chinese tradition of Confucianism, research on Paternalistic leadership (PL) has been born in Taiwan and boomed in western scholars in the past thirty years, while studies in this aspect is still relatively scare in South Korea This study regards $P L$ as research object, introduces organizational identification (OI) as intermediary variable to find out the impact on organizational commitment (OC), while the status of behavior of employees in South Korea, organizations is analyzed, using a sample $(N=300)$ of working professionals enrolled in an executive MBA program in a university in South Korea. Results showed that the authoritarian dimension of PL had no impact on OC, while the benevolence dimension and morality dimension related positively to OC. In addition, Authoritarianism related negatively to OI, while both benevolence and morality related positively to OI; OI had intermediary roles in the impact of benevolence dimension and morality dimension on value commitment (VC). And the mediating effect of $\mathrm{OI}$ was investigated relationship between morality dimension and commitment to stay (CTS). Limitations of the study, directions for future research, and implications of the findings are discussed.
\end{abstract}

Index Terms-Paternalistic leadership, organizational commitment, organizational identification, confucianism.

\section{INTRODUCTION}

As globalization progresses rapidly and competition among global companies accelerates, the uncertainty of the management environment is maximized. To survive and grow in this rapidly changing environment, the management organization needs leadership that can actively cope with the change of society and improve the performance of the employees by improving the performance of the employees [1]. Research on leadership has continued with the emergence of business administration, and the fundamental roots of the research have been developed based on the social, economic and cultural background of the Western culture. If we directly apply the leadership theory in the Western culture in the oriental culture, the result may be the opposite of expectation [2].

Various researches (e.g., [3], [4]) have shown through empirical studies that patriarchal leadership exists extensively

Manuscript received November 25, 2016; revised March 12, 2017. This work was supported in part by the Korea Research Foundation BK21 Plus.

H. H. Wang is with the Department of Personnel Management \& Organization, Pusan National University, Korea (e-mail: xueni1202@gmail.com)

J. K. Kim is with the Department of Business administration, School of business, Pusan National University, Korea (e-mail: jkk@pusan.ac.kr). in Chinese corporate organizations. The successful entrepreneurs in China are Wang Chun-fu, Chairman of BYD Automobile, Zhang Rui-min, CEO of Haier Group, Lenovo Chairman Liu Chuan-zhi, Huawei Group, Chairman Ren Zheng-fei (non-executive director) are active in modern business management with the paternalistic leadership. Benefit from paternalistic leadership, the companies mentioned above have been able to maintain market value gains and continuous innovation, and become the industry leader [5]. However, as a result of summarizing these studies about PL, there was an inconsistent, even totally contradictory result about whether PL (paternalistic leadership) affects the identification of employees, whether employees can improve their trust with leaders or improve organizational performance [6], [7].

On the other hand, the research on PL has been carried out variously in China, Japan, etc. in East Asian cultures. However, there have been few studies conducted on geographically adjacent and homogeneous Korea. The main reason is that most scholars perceive PL as simply authoritarian and passive patriarchal leadership. In addition, in Korea, studies on bureaucratic organizational culture have not been actively studied because authoritarianism does not directly affect organizational commitment. However, recent studies of PL have emerged that have moved away from authoritarianism. In the same Confucian culture, Korea is a capitalist state and China is socialism, so it is expected that there will be a difference in the effectiveness of the best leadership. From this point of view, this study is meaningful to grasp the validity of PL in modern perspective, which is a peculiar leadership in oriental culture.

It is the responsibility and responsibility of the leader to achieve organizational goals by enhancing employee satisfaction and enhancing OC (organizational commitment) [8]. However, due to various macroscopic factors, management's expectation pressure on employees has intensified so that the feeling of belonging to their organizations is getting weaker. OI (organizational identification) can be an important factor that increases the satisfaction of the organization and increases the commitment to the organization. Therefore, this study set out the following research objectives in order to investigate the relationship between PL, OI, and OC in an empirical way. First, based on the previous research, we try to investigate what is the most leadership, or whether there is a relation between PL and OC, especially the relationship between multidimensional PL and multidimensional OC. Second, we want to examine the relationship between PL and OI. Finally, we examine the role 
of OI as a variable between PL and OC through empirical analysis.

The intention of this study is to find out how the PL, which is rooted in the Confucian ideology of the traditional Oriental culture, affects the affection and loyalty of the employees and how the sense of unity with the employees', the theoretical implications are presented.

\section{DERIVATION OF THEORETICAL BACKGROUND AND HYPOTHESIS}

\section{A. PL and $O C$}

Leadership research has been mature since the 20th century, but its definition has been variously defined by scholarly perspectives and research fields and is generally understood as a form of social influence. In the 1980s, as the leadership approaches that are valued, charismatic leadership, transformational leadership, and transactional leadership have been the main research subjects, leading to trends in the relationship between leadership and organizational effectiveness and job satisfaction [8].

In the 21 st century, the main leadership researches are the relationship between leadership and follower attitude behavior [9], the relationship between ethical leadership and behavior [10]. It reveals that leadership is related to behavior and attitude there is relevance. In addition, the overlap between transformational leadership and servant leadership leads to a combination of leadership initiative and modeling [11], transformational leadership and ethical leadership overlapping with moral perspectives and personal ties [12]. A common feature of contemporary leadership is a rigorous lesson for employees, personal consideration and self-virtue of the leader.

With the development of the East Asian economic integration process and the growing interest in China among the countries that have achieved rapid economic development, the research on the traditional leadership based on their distinctive traditional culture has increased. PL is effective in the Chinese business environment because it satisfies the "twin requirements (subordination and harmony)" of successful leadership [13], and has been rather criticized by Western influences for its absolute influence and power inequality [14], while Western leaders manage employees through democracy and participation [13], whereas in East Asian cultures, especially in China, arbitrary and imperative leadership is more appropriate [15]. The Republic of Korea is in a similar cultural environment to China, and it recognizes the importance of ruder as a miracle of economic development from President Park Chung-hee's five-year plan within only 50 years. Researchers who are blindly devoted to Western leadership to catch up with the pace of development begin to come up with unique leadership qualities in an oriental cultural environment. In the meantime, researchers who blindly immerse themselves in the study of western leadership to catch up with the pace of development of developed countries sooner or later begin to come up with PL, a distinctive leadership in the oriental cultural environment.

The monarchy of 3000 years in China and the three cardinal guides influenced not only China but also Korea and Japan, and assumed the status of father in the oriental culture. At the same time, legalism emphasized the importance of norms and punishment, insisted on the power concentration system, therefore the authoritarianism of the leader has been demanded. The emphasis on the ethical relationship based on the virtue, the authority, and the loyalty of the Confucian ideology has demanded the high virtue of the leader. And Confucian philosophy has been regarded as a standard of action for justice and justice, and it has been demanded of the leader's charity [2].

PL is a style in which a leader has strict discipline and authority for its employees in a hierarchical relationship, a style of compassionate guidance and high virtue as a parent [3]. In addition, it is composed of authoritarianism, benevolence, and morality as detailed constituent factors [4]. In a patriarchal cultural environment, authoritarian leaders regard their obligation and respect as the duty to provide protection to people within their control, and expect the employees to be in a state of affirmation and respect [16]. In addition, authoritarian leaders require behavior such as employee awe and aggression through behavioral changes such as hiding facial expressions and maintaining distance [3]. Benevolent leaders acting individually and the overall interest of the individual or family well-being of employees [7], [17]. PL focuses on the employee's welfare, engages in personal affairs and nerves, and expects employees in the oriental culture to reward the gratitude and give them personal respect and emotion [18]. On the other hand, in Western cultures, the personal interest is regarded as a form of exploitation of labor by private relations or invasion of privacy [14]. Moral leadership can be broadly depicted as a leader's behavior that demonstrates superior personal virtues, self-discipline, and unselfishness [3], [7].

As a universal leadership in the Oriental culture, there has been a lot of research on PL's effectiveness, particularly its influence on employee attitudes and behaviors recently. OC has been widely discussed in Organizational Behavior, numerous scholars have studied it since the $1960 \mathrm{~s}$, but there is no universal definition. In terms of OC from an attitude perspective, Allen \& Meyer (1990) 's definition of an individual' $s$ identity with a particular organization has been used extensively, which is an emotional commitment to accept the organization 's purpose and norms on its own; Continuing commitment from monetary or non-monetary compensation and welfare received through the organization, and investment in the organization; And normative commitment resulting from having long-term and moral responsibility for the organization [19]. However, this measurement of organizational commitment is valid in Europe, Wasti (2002) has shown the importance of developing emic (culture-specific) items when assessing etic (culture-general) OC constructs [20]. Porter (1976) defined $\mathrm{OC}$ as an attitude in which employees trying to recognize organizational loyalty and organizational value and to achieve organizational goals [21]. OC can be identified by employees' trust and attachment to the goals and values of the organization, their dedication to strive for the development of the organization, and their desire to remain in the organization as part of the organization [22]. OC refers to the 
psychological substance that separates individuals and organizations [23], at some point, it can be regarded as an attitude or behavioral expression, which means an oath or promise made by employees [24]. From this viewpoint, we attempt to define the value attitude of an employee as recognizing the value of the organization and internalizing the organizational goal as VC (value commitment), behaviors that are expected to remain in the organization as CTS (commitment to stay).

Stronger authoritarian leadership can cause employees to rebel and reduce their desire to engage in work [25]. PL has a low autonomy due to negative effects on creativity and internal control [4], which has negative effects on OC by stimulate employee anger sentiment [26]. Chan, Huang, Snape, \& Lam (2013) suggested that organizational-based self-esteem of employees due to authoritarianism of leaders is weakened but that this negative relationship is reduced by stronger benevolence [27]. Employees who work under high moral leader tend to be more sociable and more active in organizational citizenship behavior [28].

Erben \& Güneser (2007) demonstrates that the leader, who is the model for the employees and shows the ethically acceptable behavior, plays an important role in forming a psychologically meaningful perception of the organization's ethical processes and policies, and implies that it has an influence on the value commitment of employees [29]. Chou, Cheng, and Jen (2005), based on social exchange theory, found that employees with a high level of dependence on the organization are more likely to devote their jobs to achieving their goals, or to receive leadership attention and fair treatment [30]. Based on these arguments, this study predicted that the higher the authoritarianism, the lower the value commitment of the organizational members, and the higher the benevolence and morality, the higher the value commitment. The hypotheses are as follows.

H 1: PL will influence OC

$\mathrm{H}$ 1a: Authoritarianism will have a negative impact on VC. $\mathrm{H} 1 \mathrm{~b}$ : Benevolent will have a positive impact on VC.

$\mathrm{H} 1 \mathrm{c}$ : Morality will have a positive impact on VC

In the Western culture, the negative link to paternalism shows that paternalism is largely recognized as a dictatorship [4]. In distinguishing between paternalism and dictatorship in Western culture, PL focuses on employee welfare, rewarding leader's consideration, employees are loyal to respect and emotion, and dictatorship, on the other hand, It focuses on exploitation and adapts to the orders of the leaders by not trying to punish the employees [14].

Rehman \& Afsar (2012) suggested that authoritarianism has a more significant impact on persistent commitment than emotional commitment because employees take into account the cost of leaving the organization [31]. Erben \& Güneser (2008) suggested that people may like caring leaders who look after them but they may dislike being manipulated or being looked after in a rule-governed way which is a characteristic of authoritarian paternalism [29]. Because authoritarianism emphasizes absolute obedience, it can capture the alienation and resistance of organizational members [30]. Based on these discussions, this study predicted that authoritarianism would lower the CTS, and that benevolent and morality would increase the CTS. Hypotheses are set as follows.

H 1d: Authoritarianism will have a negative impact on CTS $\mathrm{H}$ 1e: Benevolent will have a positive effect on CTS $\mathrm{H}$ 1f: Morality will have a positive effect on CTS

\section{B. PL and $O I$}

OI is a form of psychological attachment in which employees adopt the definition of organizational characteristics in self-definition [32]. In the self-concept that expresses the innermost inner side of human beings, the organization identification is the basis of that. Tajfel \& Turner (1979) argues that based on the social identity theory, the higher the perceived self-esteem and social status are, the higher the organizational identification is [33]. And this attitude indicates that the behavior of the self is affected by comparing and evaluating the organization with which it belongs and other organizations. When an individual identifies with an organization, he or she feels a sense of unity and belonging to the organization and does not distinguish between the organization's interests and its own interests. Even without recognizing the strategies, values, or authoritarianism, as a member of the organization, one can self-concept himself or herself using the characteristics of the group to which you belong as you get answers to "who am I?" [34]. In other words, an individual identifies an organization to which he belongs as a part of his or her own.

PL plays an important role in improving organization identification. There is a tendency for employees with high authority orientation to imitate or obey the leader's behavior by positively perceiving the authoritarianism of the leader [7]. Pellegrini \& Scandura (2008) suggested that authoritarianism is perceived as a role of fathers' compassion if employees maintain trust or respect for leaders [4]. Shamir, House, \& Arthur (1993) argued that leaders increase the intrinsic value of efforts and goals by linking them to valued aspects of the follower's self-concept, thus harnessing the motivational forces of self-consistency, and self-worth [35]. Employees will have a more positive effect in achieving organizational goals, if a leader sets a clear vision [36], thus PL may has a positive effect in employees' attitude toward the job through strict coaching and this attitude will expand to the organization [25].

Research on authentic leadership shows that leaders make employees feel a sense of homogeneity to the leader and take pride in belonging to the organization by demonstrating high individual morality, honesty and integrity (e. g., role modeling) [9]. Reference [37] shows that the high morality of ethical leaders has a positive impact on the symbolization and internalization of employees' identities. Based on these discussions, this study predicted that PL would have a positive effect on employees' identification of organizations, and the following hypothesis was drawn

\section{H 2: PL will have a positive effect on OI.}

\section{Mediating Effect of $\mathrm{OI}$}

Reference [37] shows that OI directly affects organizational citizenship behavior and job involvement. As 
an extension of individual's perspective to the organization's perspective, OI enables the employees to have the idea of willing to sacrifice and make more efforts for the organization. Rehman \& Afsar (2012) suggested that leaders can endow a sense of identity to their employees through personal or universal affection, consequently, the employees recognized that there will not be such good leaders anywhere else, so they were less likely to engage in turnover and become engaged in the organization [31]. Leaders need an attitude of showing authenticity instead of an authoritarian attitude to their employees, helping them achieve their own desires and goals, and that will give them more pride and affection. The characters of servant leadership, such as, individual development and community building, are proved to significantly correlated with the behavior of Align with organization's values and goals. PL is predicted to be relevant to $\mathrm{VC}$ and CTS in terms of educating employees and listening to the personal solicitations of compassionate employees. In this discussion, PL was predicted to positively affect the degree of association of employees with the organization, and furthermore to protect and protect the organization. The hypothesis is as follows.

H 3: OI will mediate the relationship between PL and OC. $\mathrm{H}$ 3a: OI will mediate the relationship between PL and VC $\mathrm{H} 3 \mathrm{~b}$ : OI will mediate the relationship between PL and CTS.

The research model incorporating the above hypotheses is shown in <Fig. 1>

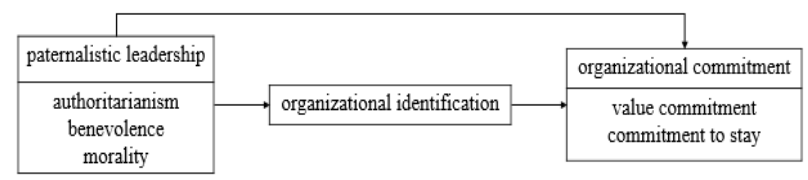

Fig. 1. Model between PL and OC.

\section{METHODS}

\section{A. Sample and Procedure}

The data $(N=300)$ were collected from working professionals enrolled in an executive MBA program at a university in South Korea. We controlled the gender, age, educational background, and working years of employees, which are external variables that employees can not recognize about PL and affect OC.

To investigate the relationship between PL, the effective leadership in China, and workers in Korea, we excluded untrustworthy questionnaire and questionnaires with a time shorter than 200 seconds. The questionnaire distribution and collection activities were conducted from March 24, 2016 to April 26, 2016 for about one month. The questionnaires were distributed and retrieved by the researchers on the Internet or by direct visits.

The research population distributed questionnaires to a total of 406 people, and 364 questionnaires were collected, showing a high recovery rate of $89.7 \%$. The 42 unsuccessful questionnaires were not collected due to the urgent delivery of respondents, personal circumstances of the respondents, and discarding e-mails. Of these, 27 were the most centralized tendency among the collected questionnaires, 19 were less than 200seconds response time on the Internet answer sheet, and 18 were uncompleted questionnaires. After excluding those questionnaires, a total of 300 questionnaires were used as valid data for final statistical analysis.

For this study, we analyzed the frequency of the demographic characteristics of the respondents. According to the analysis results, among the total 300 respondents, the male to female ratio was $67.0 \%$ and the male to female ratio was $33.0 \%$. The number of people in their 30 s is $5.3 \%$ and the number of people aged $31-40$ is $59 \%$, which is 177 people.

\section{B. Measures}

The measurement items used in this study were reconstructed according to the actual situation of Korea based on the precedent study of PL, OC and OI. The questionnaire items were set as Likert 5point scale excluding the demographic characteristics variables and were measured as 1 point (strong negative) and 5 points (strong positive). The questionnaire was composed of the most leadership, organizational commitment, the questionnaire consisted of 5 parts.

PL is defined as a leadership that has rules or authority, but also combines fathers' benevolence and a moral moral example according to the definition of Farh \& Cheng (2000). Based on the paternalistic leadership scale developed by Cheng (1995) and revised by Farh \& Cheng (2000), the authoritarianism 8 items, benevolence 11 items, morality 5 items total of 24 items were used and measured. All survey items had a 5-point response format with higher scores representing higher PL. For example, to measure authoritarianism in response to questions such as "My supervisor determined all decisions in the organization whether they are important or not"; to measure benevolence, we used questions such as "My supervisor takes good care of my family members as well", and in order to measure morality, items like "My supervisor scolds us when we can't accomplish our tasks" are used. The internal reliability coefficient was 0.94 for the benevolence scale, 0.90 for the morality scale, and 0.89 for the authoritarianism scale.

$\mathrm{OC}$ is defined as the desire to recognize, strongly accept, and remain in the organization the goals and values of the organization in accordance with Porter (1976). The measurement of OC is based on the 12 items used in the study by Angle \& Perry (1981). All survey items had a 5-point response format with higher scores representing higher commitment. For example, VC is measured using the item as "I feel a strong sense of belonging to our organization", In addition, to measure CTS, items like "I think that a person who follows the organization's management policy is desirable as a member of the organization," and "One of the negative consequences of quitting this company is that there are few companies to be hired again." are used. The internal reliability coefficient was 0.89 for the VC, 0.72 for the CTS.

OI is defined based on the definition of Mael \& Ashforth (1992), which is defined as a perception of oneness with or belonging to an organization where the individual defines him or herself at least partly in terms of their organizational membership. As a measure of OI, we used 6 items from Mael 
\& Ashforth (1992). All survey items had a 5-point response format with higher scores representing higher identification. A sample item from this scale is "If a story in the media criticized the company, I would feel embarrassed". Coefficient $\alpha$ for the scale scores was 0.87 in the United States.

The variables that can externally affect OC of organizational members were controlled. The authoritarian orientation toward the authoritarian role of the leader has a moderating effect on the subordinate response, and this authoritarian orientation is related to the age and educational level of the employee [7]. In addition, Chen et al. (2010) found that organizational outcomes differed according to the gender of the subordinate employees in terms of benevolent and authoritarianism [39]. In this study, we used gender, age, educational background, position, and working seniority that would have external influences on employee's style.

\section{REsUlts}

\section{A. Descriptive Analysis}

The descriptive statistics and Cronbach's $\alpha$ coefficients for all variables, as well as the correlation coefficients among variables are presented in Table I. The bivariate correlation analysis revealed that benevolence and moral leadership were positively correlated $(r=0.41)$. Authoritarianism was negatively correlated with both morality $(r=-0.188)$ and benevolence( $r=-0.214)$. In addition, authoritarianism was negatively correlated with VC. Something interesting was that OI was positively correlated with both benevolence $(r=0.296)$ and morality ( $r=0.264)$, but was not significantly correlated with authoritarianism. With regard to OI, it exhibited a modest positive correlation with $\mathrm{VC}(r=0.620)$ and $\operatorname{CTS}(r=0.221)$.

TABLE I: MEANS, STANDARD DEVIATIONS, CORRELATIONS, AND RELIABILITIES OF MEASURES

\begin{tabular}{|c|c|c|c|c|c|c|c|c|c|c|c|}
\hline Variables & 1 & 2 & 3 & 4 & 5 & 6 & 7 & 8 & 9 & 10 & 11 \\
\hline 1. Gender & - & & & & & & & & & & \\
\hline 2. Ages & -.052 & - & & & & & & & & & \\
\hline 4. Position & $-.351^{* * *}$ & $.403^{* * *}$ & .049 & - & & & & & & & \\
\hline 5. Tenure & $-.279^{* * *}$ & $.542^{* * *}$ & .023 & $.612^{* *}$ & - & & & & & & \\
\hline 6. A & .040 & .092 & .098 & .060 & .088 & $(.830)$ & & & & & \\
\hline 8. M & -.076 & -.027 & -.045 & .043 & -.013 & $-.188^{* * *}$ & $.410^{* *}$ & $(.869)$ & & & \\
\hline 9. OI & -.004 & .048 & -.056 & -.022 & -.003 & .034 & $.296^{* *}$ & $.264^{* *}$ & $(.883)$ & & \\
\hline 10. VC & -.072 & .096 & -.025 & .054 & .055 & $-.127^{*}$ & $.423^{* *}$ & $.388^{* *}$ & $.620^{* * *}$ & $(.818)$ & \\
\hline 11. CTS & $-.142^{*}$ & $.196^{* * *}$ & -.030 & $.215^{* *}$ & $.307^{* * *}$ & .053 & .106 & $.222^{* *}$ & $.221^{* * *}$ & $.327^{* * *}$ & (.688) \\
\hline $\mathrm{M}$ & 1.32 & 2.38 & 3.2 & 2.25 & 3.36 & 3.116 & 3.372 & 3.822 & 3.952 & 3.713 & 3.465 \\
\hline SD & 0.496 & 0.715 & 0.573 & 1.169 & 1.425 & 0.836 & 0.771 & 0.858 & 0.746 & 0.817 & 0.837 \\
\hline
\end{tabular}

Note: $N=300 . * p<.05, * * p<.01, * * * p<0.001$

$\mathrm{OI}=$ organizational identification, $\mathrm{VC}=$ value commitment, $\mathrm{CTS}=$ commitment to stay; $\mathrm{A}=$ authoritarianism; $\mathrm{B}=\mathrm{benevolence}$; $\mathrm{M}=$ morality.

Reliability coefficients appear along the diagonal.

TABLE II: THE RELATIONSHIP OF PL, OC, OI

\begin{tabular}{|c|c|c|c|c|c|c|c|c|c|c|c|c|}
\hline & \multicolumn{4}{|c|}{$\mathrm{OCC}(\mathrm{VC})$} & \multicolumn{4}{|c|}{ "OC(CTS) } & \multicolumn{4}{|c|}{$\overline{\mathrm{OOI}}$} \\
\hline & \multicolumn{2}{|c|}{ M1 } & \multicolumn{2}{|c|}{ M2 } & \multicolumn{2}{|c|}{ M1 } & \multicolumn{2}{|c|}{ M2 } & \multicolumn{2}{|c|}{ M1 } & \multicolumn{2}{|c|}{ M2 } \\
\hline & $\beta$ & $t$ & $\beta$ & $t$ & $\beta$ & $t$ & $\beta$ & $t$ & $\beta$ & $t$ & $\beta$ & $t$ \\
\hline Gender & -.087 & -1.324 & -.025 & -.426 & -.064 & -1.035 & -.048 & -.796 & -.025 & -.371 & .010 & .165 \\
\hline Ages & .096 & 1.368 & .111 & 1.788 & .051 & .768 & .052 & .800 & .072 & 1.008 & .071 & 1.052 \\
\hline Education & -.029 & -.470 & -.022 & -.413 & -.025 & -.440 & -.025 & -.463 & -.014 & -.226 & -.025 & -.424 \\
\hline Position & .051 & .640 & .029 & .418 & .006 & .076 & -.009 & -.129 & -.012 & -.153 & -.025 & -.328 \\
\hline Tenure & -.031 & -.338 & -.019 & -.231 & .255 & $3.276^{* *}$ & .268 & $3.528^{* * * * *}$ & -.010 & -.114 & .004 & .044 \\
\hline A & & & -.012 & -.217 & & & .075 & 1.342 & & & .126 & $2.194^{*}$ \\
\hline B & & & .307 & $5.361^{* * * *}$ & & & .059 & .974 & & & .238 & $3.865^{* * * *}$ \\
\hline M & & & .258 & $4.574^{* * * *}$ & & & .214 & $3.586^{* * * *}$ & & & .196 & $3.219^{*}$ \\
\hline $\mathrm{F}$ & \multicolumn{2}{|c|}{1.381} & \multicolumn{2}{|c|}{9.871} & \multicolumn{2}{|c|}{5.795} & \multicolumn{2}{|c|}{6.270} & \multicolumn{2}{|c|}{0.369} & \multicolumn{2}{|c|}{4.482} \\
\hline$R^{2}$ & \multicolumn{2}{|c|}{.032} & \multicolumn{2}{|c|}{.255} & \multicolumn{2}{|c|}{.106} & \multicolumn{2}{|c|}{.163} & \multicolumn{2}{|c|}{.009} & \multicolumn{2}{|c|}{.134} \\
\hline$\Delta R^{2}$ & \multicolumn{2}{|c|}{.009} & \multicolumn{2}{|c|}{.229} & \multicolumn{2}{|c|}{.088} & \multicolumn{2}{|c|}{.137} & \multicolumn{2}{|c|}{-.015} & \multicolumn{2}{|c|}{.104} \\
\hline
\end{tabular}

Note: $N=300 . * p<.05, * * p<.01, * * * p<0.001$

$\mathrm{OI}=$ organizational identification, $\mathrm{OC}=$ organizational commitment, $\mathrm{VC}=$ value commitment, $\mathrm{CTS}=$ commitment to stay; $\mathrm{A}=$ authoritarianism; $\mathrm{B}=$ benevolence; $\mathrm{M}=$ morality.

\section{B. Hypotheses Testing}

In order to test the research hypothesis, regression analysis was conducted based on the previous analysis. In testing Hypotheses 1a, 1b, 1c, and 1d, 1e, 1f, we simultaneously entered the three dimensions of PL (authoritarianism, benevolence, morality) and OC (VC, CTS) in the SPSS and entered employee's gender, age, education, and tenure and leader's gender as control variables. The results are presented in Table II M2 about VC. It can be seen that between authoritarianism and VC, the correlation was negative but not 
significant $(\beta=-0.12)$. In addition, both benevolence and morality were positively related to $\operatorname{VC}\left(\beta_{1}=0.307, p<0.001\right.$; $\left.\beta_{2}=0.258, p<0.01\right)$. However, as presented, neither authoritarianism nor benevolence related to CTS, while morality was positively related to it $(\beta=0.214, p<0.001)$. Those findings support Hypotheses $1 \mathrm{~b}, 1 \mathrm{~d}$, and 1f, however, Hypotheses 1a, 1d, and 1e were not completely supported. To test Hypotheses 2a, 2b, and 2c, all of the dimensions (authoritarianism, benevolence, morality) of PL were positively related to OI, and benevolence is the most significant $(\beta=3.865, p<0.001)$.

To test the mediating effect, we used Baron and Kenny's three-step method: (1) independent variables had significant effect on the dependent variable. (2) The independent variables have significant effects on the mediating variables. (3) After adding the mediating variable, the significance of the dependent variable of the independent variable was decreased or disappeared. To test Hypotheses 3a, and $3 \mathrm{~b}$ that OI mediates all the relationships between PL and OC, Table III shows that no significant relationship was found between authoritarianism and OC. In M3 of VC, the $\beta$ value of benevolence was lowered from 0.307 to 0.182 , and morality decreased from .258 to .156 . The value of $\mathrm{R}^{2}$ also increased by $23.6 \%$ from 0.255 to 0.491 . To test Hypothesis $3 \mathrm{~b}$, as presented in M3 of CTS, the $\beta$ value of morality decreased from 0.214 to 0.183 , and $\mathrm{R}^{2}$ also increased by $20 \%$ from .163 to .186 . In sum, as presented in Table III, the results support the mediating effects of OI in the relationships between (1) benevolence and morality of PL and VC and (2) morality of PL and CTS. Meanwhile, these results suggest that OI does not play a mediating role between authoritarianism and OC.

TABLE III: THE MEDIATING ROLE OF OI

\begin{tabular}{|c|c|c|c|c|c|c|c|c|c|c|c|c|}
\hline & \multicolumn{6}{|c|}{$\mathrm{OC}(\mathrm{VC})$} & \multicolumn{6}{|c|}{ OC(CTS) } \\
\hline & \multicolumn{2}{|c|}{ M1 } & \multicolumn{2}{|c|}{ M2 } & \multicolumn{2}{|c|}{ M3 } & \multicolumn{2}{|c|}{ M1 } & \multicolumn{2}{|c|}{ M2 } & \multicolumn{2}{|c|}{ M3 } \\
\hline & $\beta$ & $t$ & $\beta$ & $t$ & $\beta$ & $t$ & $\beta$ & $t$ & $\beta$ & $t$ & $\beta$ & $t$ \\
\hline Gender & -.087 & -1.324 & -.025 & -.426 & -.031 & -.627 & -.064 & -1.035 & -.048 & -.796 & -.054 & -.911 \\
\hline Ages & .096 & 1.368 & .111 & 1.788 & .074 & 1.442 & .051 & .768 & .052 & .800 & .041 & .637 \\
\hline Education & -.029 & -.470 & -.022 & -.413 & -.009 & -.210 & -.025 & -.440 & -.025 & -.463 & -.013 & -.243 \\
\hline Position & .051 & .640 & .029 & .418 & .042 & .728 & .006 & .076 & -.009 & -.129 & -.002 & -.031 \\
\hline Tenure & -.031 & -.338 & -.019 & -.231 & -.021 & -.309 & .255 & $3.276^{* * *}$ & .268 & $3.528^{* * * *}$ & .267 & $3.554^{* * * * *}$ \\
\hline A & & & -.012 & -.217 & -.078 & -1.741 & & & .075 & 1.342 & .055 & .982 \\
\hline B & & & .307 & $5.361^{* * * * *}$ & .182 & $3.751^{* * * *}$ & & & .059 & .974 & .017 & .275 \\
\hline M & & & .258 & $4.574^{* * * *}$ & .156 & $3.278^{* * *}$ & & & .214 & $3.586^{* * * *}$ & .183 & $3.063^{* *}$ \\
\hline OI & & & & & .523 & $11.570^{* * * *}$ & & & & & .165 & $2.884^{* *}$ \\
\hline $\mathrm{F}$ & & & & & & .269 & & & & 270 & & 617 \\
\hline$R^{2}$ & & & & & & 491 & & & & 63 & & 86 \\
\hline$\Delta R^{2}$ & & & & & & 472 & & & & 37 & & 58 \\
\hline
\end{tabular}

Note: $N=300 . * p<.05, * * p<.01, * * * p<0.001$

$\mathrm{OI}=$ organizational identification, $\mathrm{OC}=$ organizational commitment, $\mathrm{VC}=$ value commitment, $\mathrm{CTS}=$ commitment to stay; $\mathrm{A}=$ authoritarianism; $\mathrm{B}=\mathrm{benevolence}$ $\mathrm{M}=$ morality.

\section{DisCUSSION}

Although the importance of paternalism in leadership has been considered for decades (e.g., Weber, 1947), it has not been systematically investigated until recently. Moreover, as rooted on Chinese traditional culture, culture-context tended to be considered as the main reason leading to different effects. We follow this trend and had tested the effectiveness of PL in Korea, which is bordered by China with the same Confucian cultural context, but with the capitalist system. As hypothesized, unlike previous research we found that not all three dimensions of PL are related to employee OC. Whereas both benevolence and morality had positive relationships with VC, authoritarianism had no significant relationship with OC in fact. Moreover, we found that only morality had significant positive relationship with CTS. More importantly, we found that OI played a mediating role between leader benevolence, morality and VC, as well as between morality and CTS, whereas OI was not significantly related to authoritarianism at all.

These findings are intriguing. Because it shows the prominence of $\mathrm{OI}$ in translating morality and benevolence into $\mathrm{VC}$, and morality into CTS. In previous studies, there are so many different results on the relationships of PL and employees' performance (e. g., [7], [17]). Whether the cultural context is a boundary condition lies in the fit between the style of a leader and that of his or her followers [4]. The two unexpected findings, that is, OI did not mediate the relationship between benevolence and CTS, and there is a positive correlation between authoritarianism and OI, but it has no significant relationship with $\mathrm{OC}$, are also intriguing. We offer several explanations below.

A plausible explanation regarding the insignificant role of OI in relating benevolence to the CTS dimension of OC may be related to the nature of OC. As Chinese thought deeply rooted in human relationships [39], leadership's benevolence stimulates the harmony with the employees but does not 
require the emotional attachment of the employees. Likewise, unlike emotional ties with leaders, protecting organizational resources is likely to be a duty or compliance. Because employees who obey the rules should not use company resources for personal gain. Also, employees of benevolent leaders can continue to exist within an organization even if they do not define themselves through it.

The explanations for the nonsignificant relationship between authoritarianism and OC may involve many aspects. Previous research has shown that authoritarianism can lead to employee dissatisfaction and negative emotions such as fear and anger [26], but OC seems unaffected by authoritarianism, indicating that there may be significant differences in composition of emotions and commitment. In China, people respect the authority associated with hierarchical positions [17], even though they experience negative emotions created from the authority of their leaders, their commitment load may retain intact. Meanwhile, this finding suggests that other mechanism may heightened external pressure to perform. It may relate to the changes in economic conditions and development of Korea. According to the Korea Central Bank, as of the end of 2015, South Korea's total household indebtedness for the first time more than 1200 trillion won, to 1207 trillion won, an increase of $11.2 \%$ (121.7 trillion won), which is the largest increase in history. It is worth mentioning that, at present, South Korean household debt growth has far exceeded the amount of consumption growth, the per capita debt up to 24 million won. Faced with such severe economic pressures, even if the leadership is authoritarian, workers still will not leave the company in order to maintain normal daily expenses.

PL is rooted in traditional Oriental Confucian cultural environments. Therefore, previous researches on the PL have been conducted mainly in oriental cultures such as family business, new venture business, and simple technology gear in Taiwan. Suggesting that employees with a higher educational background would be more resistant to the authoritarianism of the leader [7]. This study was conducted to select the people who work in the MBA course with a relatively high level of academic ability or position. As a result, academic achievement did not appear to be statistically significant to the PL. This study examined the existence of PL in Korea, which was also influenced by Confucianism as China. And this study can be reinterpreted the relationship between leadership and identity through analysis of causal relationship between PL and OI. In other words, through the authoritarianism, benevolence and morality of the leader, the employee recognizes his or her value and identity related to the organization. It also showed that PL is an important preliminary variable in forming the sense of self concept and sense of unity in the organization of the employees themselves.

The results of our study should be interpreted in light of the following methodological limitations. First, it is necessary to revalidate the PL scale. The measurement scale of this study is an adaptation of China Taiwan prior study. It seems that there is a lack of literature or empirical research on the PL in the domestic environment, so it is necessary to reexamination the effectiveness of the PL scale in the domestic environment.

Second, due to limitations related to the sampling subjects of empirical studies, the working years of Korean workers are unbalanced. Employees who have worked for more than 10 years have the highest percentage, so they may become accustomed to the leadership of the leader, which may change their perception of authoritarianism. In this paper, authoritarianism of the most leadership shows the relationship between justice and equity, but the appropriate discipline and criticism of the leader can help the employee to recognize his mistake and to display a better image, and it is expected that the employees will feel emotion and worship of the leader after achieving the goal.

Finally, a longitudinal study with temporal intervals is particularly needed to verify causal relationships between research variables, but this study relies on cross - sectional studies. Therefore, in future research, it is necessary to analyze the response of survey respondents according to changes in the corporate environment over a period of time, through a longitudinal research design, and then to test the causal relationship between the variables.

\section{REFERENCES}

[1] J. W. Kim, S. H. Chae, and S. H. Bae, "The multidimensional relationship of transformational leadership, supervisor trust, and organizational commitment: Verifying the moderating effect of direct effects of trust," Korean Academy of Organization and Management, vol. 29, no. 4, pp. 31-62, Dec. 2005.

[2] B. S. Cheng, L. F. Chou, and J. L. Farh, "A triad model of paternalistic leadership: The constructs and measurement," Indigenous Psychological Research in Chinese Societies, vol. 14, pp. 3-64, 2000.

[3] B. S. Cheng, "Paternalistic authority and leadership: A case study of a Taiwanese CEO," Bulletin of the Institute of Ethnology Academic Sinica, vol. 79, pp. 119-173, 1995.

[4] E. K. Pellegrini and T. A. Scandura, Paternalistic leadership: a review and agenda for future research. Journal of Management, vol. 34, no. 3 , pp. 566-593. June 2008.

[5] A. Gao, "Effectiveness of paternalistic leadership in Chinese context," Doctoral dissertation, Tsinghua University, p. 1, 2013, China.

[6] B. S. Cheng, L. F. Chou, M. P. Huang, J. L. Farh, and S. Q. Peng, "The ternary model of paternalistic leadership: Evidence from mainland China," Idigenous Psychological Research in Chinese Societies, vol. 20, pp. 209-250, 2003.

[7] B. S. Cheng, L. F. Chou, T. Y. Wu, M. P. Huang, and J. L. Farh, "Paternalistic leadership and subordinate responses: Establishing a leadership model in Chinese organizations," Asia Journal of Social Psychology, vol. 7, pp. 89-117, 2004.

[8] B. M. Bass, B. J. Avolio, and L. Alwater, "The transformational and transactional leadership of men and women," An International Review, vol. 45, no. 1, pp. 5-34. Jan. 1996.

[9] B. J. Avolio, W. L. Gardner, F. O. Walumbwa, F. Luthans, and D. R May, "Unlocking the mask: a look at the process by which authentic leaders impact follower attitudes and behaviors," The Leadership Quarterly, vol. 15, no. 6, pp. 801-823, Dec. 2004.

[10] D. M. Mayer, K. Aquino, R. L. Greenbaum, and M. Kuenzi, “Alumni and their alma mater: A partial test of the reformulated model of organizational identification," Journal of Organizational Behavior, vol. 13, pp. 103-123, Oct. 1992.

[11] B. N. Smith, R. V. Montagno, and T. N. Kuzmenko, "Transformational and servant leadership: Context and contextual comparisons," Journal of Leadership and Organizational Studies, vol. 10, no. 4, pp. 80-91, 2004.

[12] F. O. Walumbwa, B. J. Avolio, W. L. Gardner, T. S. Wernsing, and S. J. Peterson, "Authentic leadership: development and validation of a theory-based measure," Journal of Management, vol. 34, no. 1, pp. 89-126, Feb. 2008

[13] R. L. Westwood, "Harmony and patriarchy: The cultural basis for paternalistic leadership among the overseas Chinese," Organization Studies, vol. 18, no. 3, pp. 445-480, May 1997.

[14] Z. Aycan, "Paternalism: Towards conceptual refinement and operationalization," in Indigenous and Cultural Psychology: Understanding People in Context, U. Kim, K. S. Yang, and K. K. Hwang, Eds. London: Cambridge Univ, 2006. ch. 20. pp. 445-466. 
[15] Y. Xu, "Authoritarianism: Theory, development and dilemma," Political Science Research, vol. 12, pp. 83-91. 2013.

[16] Z. Aycan, R. N. Kanungo, and J. B. P. Sinha, "Organizational culture and human resource management practices the model of culture fit," Journal of Cross-Cultural Psychology, vol. 30, no. 4, pp. 501-526, July 1999.

[17] X. P. Chen, M. B. Eberly, T. J. Chiang, J. L. Farh, and B. S. Cheng, "Affective trust in Chinese leaders: Linking paternalistic leadership to employee performance," Journal of Management, vol. 40, no. 3, pp. 796-819, Mar. 2014

[18] M. J. Gelfand, M. Eres, and Z. Aycan, "Cross-cultural organizational behavior," Annual Review of Psychology, vol. 58, pp. 479-514. Oct 2007.

[19] N. J. Allen and J. P. Meyer, "The measurement and antecedents of affective, continuance and normative commitment to the organization," Journal of Occupational Psychology, vol. 63, pp. 1-18, Mar. 1990.

[20] S. A. Wasti, "Affective and continuance commitment to the organization: Test of an integrated model in the Turkish context," International Journal of Intercultural Relations, vol. 26, pp. 525-550, Oct. 2002.

[21] L. W. Porter, W. J. Crampon, and F. J. Smith, "Organizational commitment and managerial turnover: A longitudinal study," Organizational Behavior and Human Performance, vol. 15, no. 1, pp. 87-98, Feb. 1976.

[22] R. T. Mowday, R. M. Steers, and L. W. Porter, "The measurement of organizational commitment," Journal of Vocational Behavior, vol. 14 no. 2, pp. 224-247. Apr. 1979.

[23] D. van Knippenberg and E. Sleebos, "Organizational identification versus organizational commitment: Self-definition, social exchange, and job attitudes," Journal of Organization Behavior, vol. 27, no. 5, pp. 571-584, Aug. 2006.

[24] G. Cheney and P. K. Tompkins, "Coming to terms with organizational identification and commitment," Central States Speech Journal, vol. 38, no. 1, pp. 1-15, 1987.

[25] M. Y. Cheng and L. Wang, "The mediating effect of ethical climate on the relationship between paternalistic leadership and team identification: A team-level analysis in the Chinese context," Journal of Business Ethics, vol. 129, no. 3, pp. 639-654, Jul. 2015.

[26] J. L. Farh, B. S. Cheng, L. F. Chou, and X. P. Chu, "Authority and benevolence: employee's responses to paternalistic leadership in China," in China's Domestic Private Firms: Multidisciplinary Perspectives on Management and Performance, A. S. Tsui, Y. Bian, and L. Cheng, Eds. New York: Sharpe, 2006, pp. 230-260.

[27] S. C. H. Chan, X. Huang et al., "The Janus face of paternalistic leaders: Authoritarianism, benevolence, subordinate's organization-based self-esteem, and performance," Journal of Organizational Behavior, vol. 34, no. 1, pp. 108-128, Jan. 2013.

[28] H. R. Yeh, H. K. Chi, and C. Y. Chiou, "The influences of paternalistic leadership, job stress, and organizational commitment on organizational performance: An empirical study of policemen in Taiwan," The Journal of International Management Studies, vol. 3, no. 2, pp. 85-91, 2008

[29] G. S. Erben and A. B. Güneser, "The relationship between paternalistic leadership and organizational commitment: Investigating the role of climate regarding ethics," Journal of Business Ethics, vol. 82, no. 4, pp. 955-968. Nov. 2008

[30] L. F. Chou, B. S. Cheng, and C. K. Jen, "The contingent model of paternalistic leadership: Subordinate dependence and leader competence," presented at the Meeting of the Academy of Management, Hawaii: Honolulu. 2005

[31] M. Rehman and B. Afsar, "The impact of paternalistic leadership on organizational commitment and organizational citizenship behavior," Journal of Business Management and Applied Economics, issue 5. Sep. 2012.

[32] J. E. Dutton, J. M. Dukerich, and C. V. Harquail, "Organizational images and member identification," Administrative Science Quarterly, vol. 39, pp. 239-263, Jun. 1994.

[33] H. Tajfel and J. Turner, "An integrative theory of intergroup conflict," in The Social Psychology of Intergroup Relations, W. G. Austin and S. Worchel, Eds. Monterey, CA: Wadsworth, 1979, Ch. 3, pp. 33-47.

[34] B. E. Ashforth and F. Meal, "Social identify theory and the organization," Academy of Management Review, vol. 14, no. 1, pp. 20-39, Jan. 1989.

[35] B. Shamir, R. J. House, and M. B. Arthur, "The motivational effects of charismatic leadership: A self-concept based theory," Organizational Science, vol. 4, no. 4, pp. 577-594, Nov. 1993

[36] B. M. Bass, Bass \& Stocdill's Handbook of Leadership: Theory, Research, and Managerial Applications, 3rd ed. NY, US: Free Press. 1990.

[37] D, M. Mayer, K. Aquino, R. L. Greenbaum, and M. Kuenzi, "Who displays ethical leadership, and why does it matter? An examination of antecedents and consequences of ethical leadership," Academy of Management Journal, vol. 55, no. 1, pp. 151-171, Feb. 2012.

[38] W. H. Kim, "Cross-validity model of organizational identification leading variables, organizational citizenship behavior, organizational commitment, and job involvement," Korean Academy of Organization and Management, vol. 27, no. 1, pp. 11-31, Mar. 2003.

[39] C. C. Chen and J. L. Farh, "Developments in understanding Chinese leadership: Paternalism and its elaborations, moderations, and alternatives," in Oxford Handbook of Chinese Psychology, H. B. Michael, Ed. Oxford: Oxford Univ., 2010, pp. 599-622.

[40] J. L. Farh, P. C. Early, and S. C. Lin, "Impetus for an action: A cultural analysis of justice and organizational citizenship behavior in Chinese society," Administrative Science Quarterly. vol. 42, pp. 421-444, Sep. 1997.

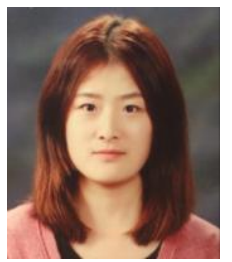

Huanhuan Wang was born in Henan Province, China on Dec. 2, 1991. She got the bachelor of Korean language in LiaoCheng University, China from Sep. 2010 to Jun. 2014, master of business administration in Pusan National University, Korea from Sep. 2014 to Aug. 2016, and from Sep. 2016, she is a doctoral candidate, her major field is in HRM, organizational behavior.

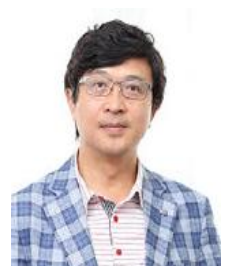

Kim Jongkuan was born in Pusan, Korea. In Feb. 1986, he got the bachelor of business administration in Pusan National University, Korea; In Feb. 1988, he got the master of business administration in Pusan National University, Korea; In Feb. 1994, he got the doctor of business administration in Pusan National University, Korea; And From Sep. 1997, He is professor in School of Business, Pusan National University, Korea. His major field is in HRM, labor relations. 